\title{
Adsorption of Aluminum, Arsenic and Sulphate Ions from Synthetic and Real Underground Water by Marine Fouling
}

Saeyda A. El-Enein, Ahmed H. Mangoode, Fathy A. Elsayed, Mahmoud A. Hammad*

Chemistry Department, Faculty of Science, Menoufia University, Egypt

\section{Retraction Note:}

The article entitled "Adsorption of Aluminum, Arsenic and Sulphate Ions from Synthetic and Real Underground Water by Marine Fouling" has been accepted for publication in the International Journal of Waste Resources considering the statements provided in the article as personal opinion of the author which was found not having any conflict or biasness towards anything. As the article was a perspective one, information provided by the author was considered as an opinion to be expressed through publication.

Publisher took decision to make the article online solely based on the reviewers suggestion which considered the article not but a personal opinion of the author. However, it is found that the author have some personal concerns and issues, therefore, being retracted from the journal. 